\title{
Effect of Tempering and Strain on Decomposition of Metastable Austenite in X210CrW12 Thixo-Cast Steel
}

\author{
t. Rogal, J.T. Bonarski, and P. Bobrowski
}

\author{
(Submitted August 3, 2015; published online February 3, 2016)
}

\begin{abstract}
Thixoforming of hot rolled $\mathrm{X} 210 \mathrm{CrW12tool}$ steel led to the formation of globular austenitic grains (82.4 vol.\%) surrounded by eutectic mixture ( $\alpha-\mathrm{Fe}$ and $\mathrm{M}_{7} \mathrm{C}_{3}$ carbides). The thixo-cast steel reached compression strength $4.8 \mathrm{GPa}$ at plastic strain $34 \%$. The analysis of pole figures after deformation indicated distinct texturization of microstructure in comparison with undeformed steel. Main texture components for austenite were $\{101\},\langle 010\rangle$, while ferrite did not reveal clearly formed orientation. DSC analysis confirmed that austenitic structure in the $\mathrm{X} 210 \mathrm{CrW} 12$ steel was metastable and temperature of decomposition depended on the strain applied at $634{ }^{\circ} \mathrm{C}$ for the un-deformed sample and at $599{ }^{\circ} \mathrm{C}$ for sample compressed up to $4.8 \mathrm{GPa}$. Discontinuous transformation of austenite into perlite, that started mainly at grain boundaries and proceeded to the center, was the predominant mechanism responsible for the decomposition of globular grains in thixoformed $\mathrm{X} 210 \mathrm{CrW12}$ steel. The decomposition caused by tempering of supersaturated and severely strained steel led to obtaining characteristic product of transformation of higher hardness in comparison with only tempered sample. In the deformed sample the reaction started on slip bands and twins which revealed high density of defects, promoting precipitation of carbides, followed by local depletion in carbon as a result of $\alpha^{\prime}-\mathrm{Fe}$ formation. In contrast to non-deformed state they covered the area of grains. Two fronts of reaction $\alpha$-Fe plate $+M_{3} C \rightarrow$ mixture of $\alpha$-Fe and $M_{7} C_{3}$ carbides were also observed.
\end{abstract}

Keywords TEM, thixoforming, X210CrW12 steel

\section{Introduction}

The semi-solid metal processing (SSM) has been based on a thixotropic flow of metal alloy in the solidus-liquidus temperature range. It results in a complex microstructure which consists of globular grains of supersaturated solid solution (not melted during the process) surrounded by the eutectic mixture in the amount of 15 to $80 \%$ (Ref $1-4$ ). The phase obtained directly from the liquid state forms in the solid state as the eutectic, which has higher content of carbon and alloying elements than the unmelted globular grains (Ref 5,6). It leads to various phase compositions, which may have an influence on mechanical properties (Ref 6). The possibility of controlling the liquid volume fraction enables changes of concentration of carbon and alloying elements in the solid solution during the process and can lead to obtaining superior materials. Tool steels such as M2, X220CrMoV-13-4 after SSM processing have a high content of residual austenite. In the case of X210CrW12 thixo-cast steel, the microstructure consists of fully austenitic globular grains (above $80 \mathrm{wt} . \%$ of $\gamma$-Fe) surrounded by the eutectic mixture consisting of $\mathrm{M}_{7} \mathrm{C}_{3}$ carbides, $\alpha$-Fe and $\gamma-\mathrm{Fe}$ (Ref 1, 2, 7). The austenite in the X210CrW12 steel is metastable at room temperature. Its decomposition takes place during heating (Ref 3,4$)$ or plastic deformation (Ref 11). In the range from 495 to $630^{\circ} \mathrm{C}$ depending on holding time, the

L. Rogal, J.T. Bonarski, and P. Bobrowski, Institute of Metallurgy and Materials Science of the Polish Academy of Sciences, 25 Reymonta St., 30-059 Krakow, Poland. Contact e-mail: 1.rogal@imim.pl. decomposition of austenitic structure in the X210CrW12 thixocast can proceed as the discontinuous reaction (Ref 7-9). The $\gamma-$ $\mathrm{Fe}$ subjected to mechanical loading starts flowing through slipping and twinning mechanisms. It also accommodates the deformation generated by phase transformation (Ref 10,11). Aisman et al. (Ref 12) deformed the X210CrW12 steel at 1100 to $870{ }^{\circ} \mathrm{C}$ (in the austenitic range) during cooling from the semi-solid range. They observed a refined and recrystallized microstructure consisting of ferrite, martensite and partially spheroid primary chromium carbides. The microstructure of C1.2Cr11V1.5W2.2Mo1.3Fe ledeburitic tool steel deformed above $1100{ }^{\circ} \mathrm{C}$ revealed a recrystallized structure, while below $1100{ }^{\circ} \mathrm{C}$ the fraction of dynamically recrystallized grains decreased with decreasing temperature and strain rate (Ref 13).

The mechanism of austenite decomposition in the thixo-cast X210CrW12 steel after cold plastic deformation and heating to tempering temperatures has not been precisely studied. In tool steels of similar chemical composition after the conventional treatment (rolling or forging followed by heat treatment consisting of austenitization at $950{ }^{\circ} \mathrm{C} / 30 \mathrm{~min}$ and tempering at $250{ }^{\circ} \mathrm{C} / 2 \mathrm{~h}$ ), the austenite appears mainly after quenching. Its content can reach 10 to $20 \%$. It transforms into martensite during tempering, which brings about the increase of secondary hardness (Ref 14, 15). The austenite after a conventional heat treatment contains a smaller amount of alloying elements and carbon than in the steel after SSM due to lower temperatures of the process. Nutting (Ref 16) studied the influence of prior strain on aging reactions in highly supersaturated solid solutions using DSC. It was confirmed that with increasing level of deformation, temperature peaks shifted to lower ones due to the formation of vacancies and dislocations which created clusters for the heterogeneous nucleation. The strain could additionally induce the precipitation of carbides (Ref 17). The aim of the work has been to determine the influence of 
deformed supersaturated austenitic globules on mechanisms of their decomposition in the X210CrW12 steel subjected to SSM.

\section{Experimental Procedure}

Thixo-casts were produced using a specially built prototype device. The piston velocity was $1 \mathrm{~m} / \mathrm{s}$. The locking force of the machine was $800 \mathrm{kN}$. A billet (diameter-30 $\mathrm{mm}$ and height $-30 \mathrm{~mm}$ ) of $\mathrm{X} 210 \mathrm{CrW} 12$ steel was placed in the coil of an inductive heating furnace. The temperature of feedstock was measured by a S type thermocouple. The heating time was $4 \mathrm{~min}$, during which the sample reached the temperature of $1250{ }^{\circ} \mathrm{C}$ ). The billet was then moved to a cylinder of a highpressure die-casting machine and pressed out at $35 \mathrm{kN}$ by a piston into a die, made of M2 steel, covered with $\mathrm{BN}$ and preheated to $200{ }^{\circ} \mathrm{C}$. The samples for optical microscopy were polished and etched with Nital. The metallographic studies were carried out using Leica DM IRM microscope equipped with Leica QUIN image analysis software. DuPont910 instrument was used to measure thermal effects during heating in the solid state at the rate of $20 \mathrm{~K} / \mathrm{min}$ in the argon atmosphere. The $\mathrm{X}$-ray investigations of the phase composition were performed using Co-Ka filtered radiation using Philips PW 1710 diffractometer. The analysis of microstructure was made using a scanning electron microscope, FEI SEM XL30 (FEI Company, Hillsboro, OR) equipped with energy-dispersive $\mathrm{X}$-ray spec- trometer EDAX GEMINI 4000. The microstructure and electron diffraction studies were performed using the Philips CM20 and Tecnai G2 F20, transmission electron microscopes (TEM). The samples for TEM were electropolished using Struers Tenupol-5 jet polisher (Struers, Inc., Cleveland, $\mathrm{OH}$ ) in the electrolyte consisting of 20 pet $\mathrm{HClO} 4$ and 80 pet $\mathrm{CH}_{3} \mathrm{OH}$ at subzero temperatures. The hardness measurements (by Vickers method) were carried out using Zwick/ZHU 250 (HV5) and CSM Instruments microhardness tester (CSM Instruments). The compression test was performed using the INSTRON 3382 machine. The X210CrW12 steel thixo-cast samples of size $5 \times 5 \times 7.5 \mathrm{~mm}$ were used for the compression test following the PN-57/H-04320 standard. All the studies of the microstructure, the $\mathrm{x}$-ray phase analysis and hardness of the samples after deformation were carried out on the surface parallel to the compressing strain.

The quantitative texture analysis of ferrite and austenite was carried out on thixo-casts of $\mathrm{X} 210 \mathrm{CrW} 12$ steel in as cast state and after deformation by $34 \%$, based on orientation distribution function (ODF) calculated using incomplete pole figures measured with feedback x-ray technique: for ferrite (110), (100), (211) and for austenite (111), (100), (110). The measurements of thixo-cast pole figures before the deformation were performed in the section plane perpendicular to its horizontal axis (Fig. 1a). The reference system for the pole figures can be described with axes RD-TD (RD-Rolling Direction; TD-Tangential Direction), marked in Fig. $1 \mathrm{~b}$ for the undeformed sample. Figure 1c represents the sample compressed

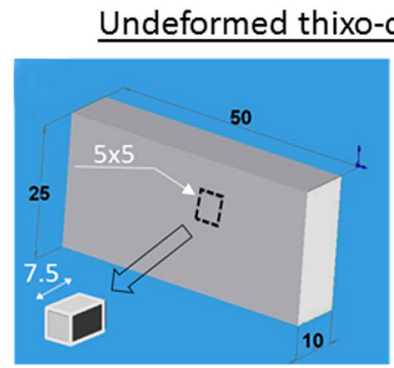

(a)

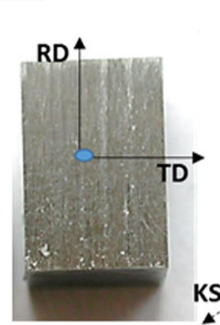

(b)

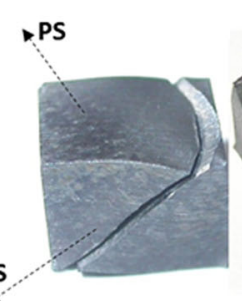

(c)
Deformed thixo-cast

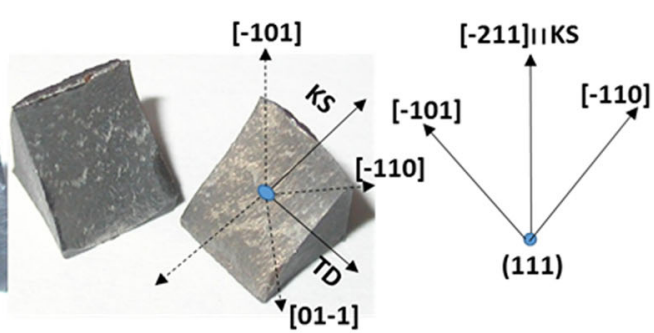

(d)

Fig. 1 Reference systems in thixo-cast texture measurements (a) area of the sample extraction (dotted line), (b) reference system (RD-TD) - undeformed thixo-cast, (c) thixo-cast deformed by $34 \%$, (d) reference system (KS-TD) - deformed thixo-cast

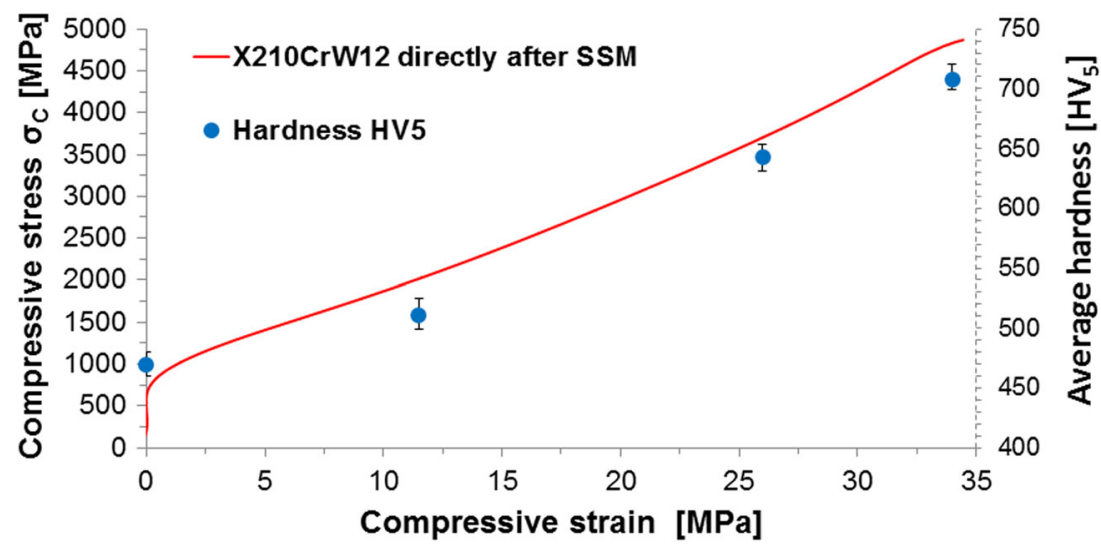

Fig. 2 Compression curves of X210CrW12 thixo-cast steel with marked values of average hardness 
at strain $4850 \mathrm{MPa}$. Its reference system is shown in Fig. 1d, in which SD-shear direction and Td-Tangential Direction are marked.

\section{Results and Discussion}

\subsection{Influence of Compression Stress on Texture}

The thixoformed X210CrW12 steel consisted of austenitic globular grains (average size $46 \mu \mathrm{m}$ ) surrounded by the eutectic mixture of $\mathrm{M}_{7} \mathrm{C}_{3}$ carbides, $\gamma$-Fe and $\alpha$-Fe (Ref 9). The compression test results of $\mathrm{X} 210 \mathrm{CrW} 12$ steel after SSM processing are shown in Fig. 2. The relatively low yield strength (YS - $810 \mathrm{MPa}$ ) was mainly due to a large fraction of austenite, which began to deform at low stress. It shows, however, a strong hardening effect resulting in very high final compression strength of $4.85 \mathrm{GPa}$. Its hardness also increased with increasing plastic strain due to the occurrence of tension. Rogal et al. (Ref 11) precisely studied the deformation of the X210CrW12 steel, which proceeded by dislocation slip and mechanical twining. Figure 3 shows the $\mathrm{x}$-ray analysis of steel in the un-deformed state (directly after SSM) and after compression at $4.8 \mathrm{GPa}$. The changes in the intensity and width of austenite peaks were observed. It may suggest that the deformation led to a decrease of the crystal size. Small shifts of

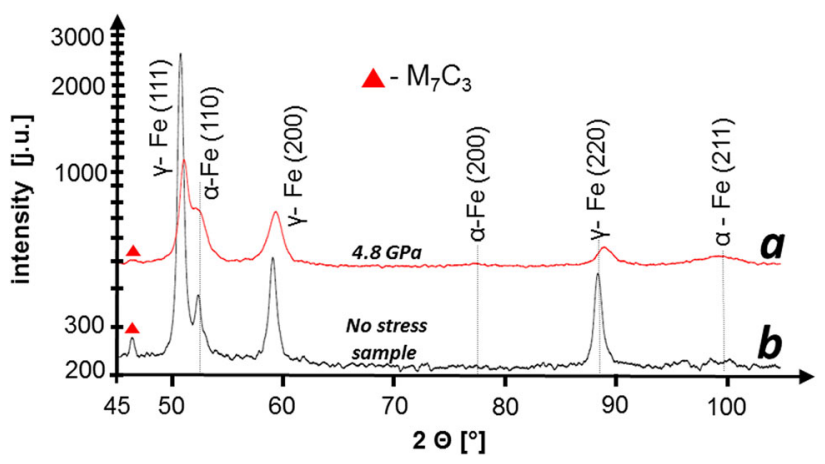

Fig. 3 X-ray analysis of X210CrW12 steel thixo-cast; (a) directly after SSM, (b) compressed up to $4.8 \mathrm{GPa}$ austenite peaks to higher $2 \theta$ values were observed due to the stresses accumulated within the deformed material, which contributed to hardening of the material. The presence of $\varepsilon-\mathrm{Fe}$ (Ref 11) was confirmed using the HRTEM analysis of highly strained area, which did not have large influence on hardening. Such a result led to the conclusion that the X210CrW12 thixocast austenite was rather mechanically stable.

The sample of the X210CrW12 steel formed with thixotropic technique revealed intensive broadening of crystallite orientation in both, the austenitic (Fig. 4a) and ferrite phases (Fig. 4b). It seems that the thixo-cast might have had properties typical for isotropic material. Figure 1c shows the sample after compression at strain $4850 \mathrm{MPa}$, which is the limit value of compression strength. The analysis of pole figures (Fig. 4a, b) indicated distinct texturization of microstructure in comparison with the un-deformed sample. The main texture components for austenite were $\{101\},\langle 010\rangle$, while ferrite did not reveal clearly formed orientation. The failure of material occurred by shear mechanism. It can be seen in (111) pole figure of austenite (Fig. 4c) with increased density of poles located close to the direction normal to the shear plane. The crystallographic slip occurred in (111) plane in [-101] and [01-1] direction, which is defined in Fig. 1d. However, due to weakly defined texture in the ferrite phase (Fig. 4b) its contribution to the mechanism of destruction has been difficult to interpret based on pole figures.

\subsection{Influence of Strain on $\gamma$-Fe Decomposition}

The austenitic structure of X210CrW12 steel after the SSP was metastable and its decomposition led to the improvement of mechanical properties (Ref 1). Positive effects of stress introduced during warm and hot plastic deformation of tool steels were reported in numerous papers (Ref 13, 17-19). In order to study the influence of stress on decomposition mechanisms of austenite at tempering temperature range, thixo-cast samples were subjected to cold plastic deformation. The strengthening effect of strain-induced transformation was observed in a Hadfield or stainless steel deformed at room temperature (Ref 20-23).

The DSC studies were conducted in order to analyze the influence of strain on temperature of austenite decomposition of the X210CrW12 thixo-cast steel. Figure 5 shows calorimetric heat flow curves for the samples: unstressed, marked as (1) and
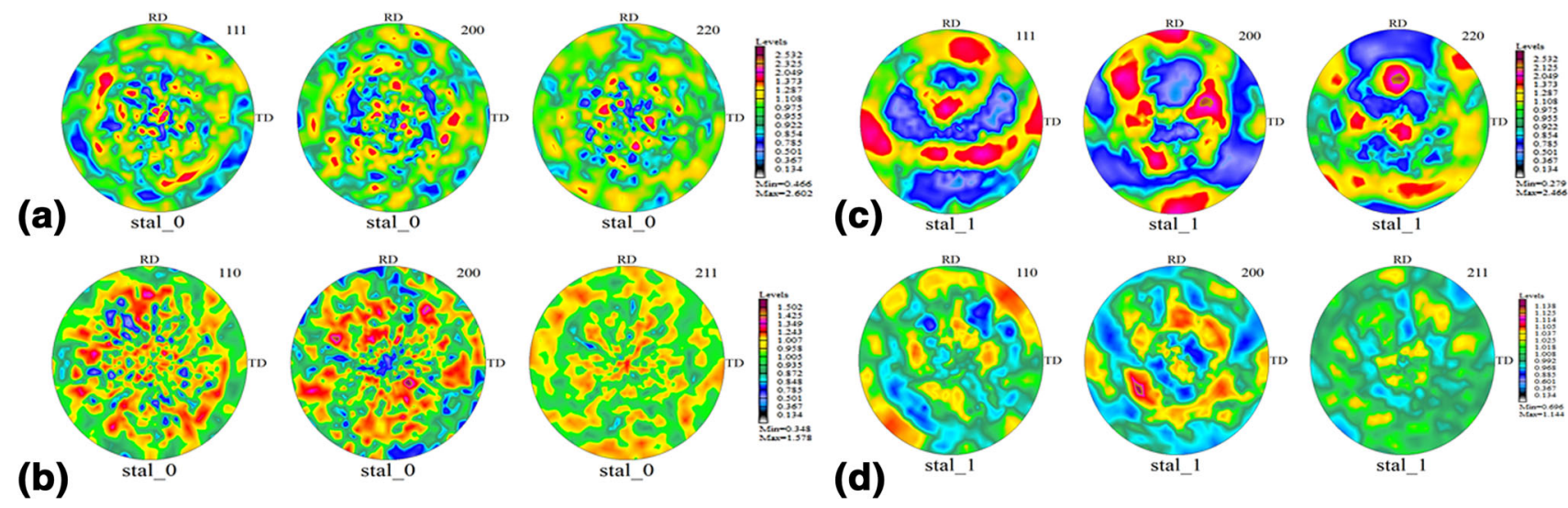

Fig. 4 (a) The $\{111\}$ pole figure of austenitic phase of X210CrW12 steel thixo-cast; (b) The $\{110\}$ pole figure of ferritic phase of X210CrW12 steel thixo-cast; (c) The $\{111\}$ pole figure of austenitic phase of X210CrW12 steel thixo-cast after compression; (d) The $\{110\}$ pole figure of ferritic phase of $\mathrm{X} 210 \mathrm{CrW} 12$ steel thixo-cast after compression 
compressed up to $4.8 \mathrm{GPa}$, marked as (4) in the temperature range of 50 to $685^{\circ} \mathrm{C}$. The magnified temperature peak in range $\left(575\right.$ to $655^{\circ} \mathrm{C}$ ) for various stressed samples: (0) - unstressed, (2)-compressed to $2 \mathrm{GPa}$, (3)-compressed to $3.8 \mathrm{GPa}$, and (4) - to $4.8 \mathrm{GPa}$ are presented in the dotted frame. The heat flow curve of the un-deformed sample (green curve with dots) showed a small exothermic effect in the temperature range from 150 to $350{ }^{\circ} \mathrm{C}$, which was probably connected with tempering of martensite. The hardness of grains slightly decreased during heating the sample up to $400{ }^{\circ} \mathrm{C}$, what could be due to the release of tension, thus suggesting that the positive effect was not related to the transformations in the austenitic grains (Ref 9). The exothermic effect of transformation of austenite globular grains into ferrite, carbides and perlite is visible in temperature range 572 to $668{ }^{\circ} \mathrm{C}$. It should be noted that the inclination angle of heat flow curve of unstressed sample is lower in comparison with the curves after deformation. It suggests that the phase transformation rate of the undeformed sample was lower. The compression strain of the

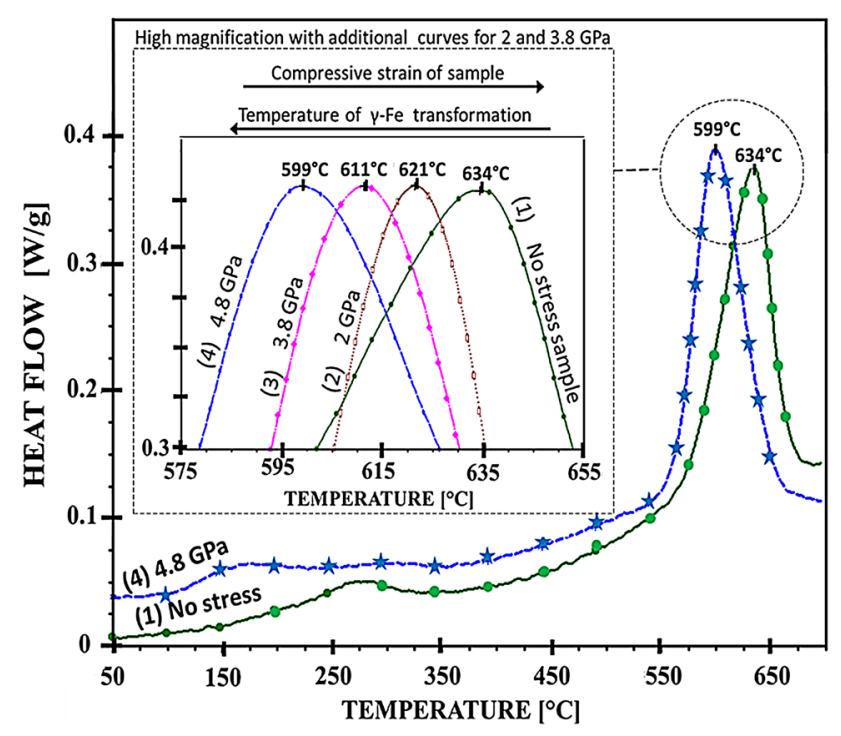

Fig. 5 DSC of the thixo-cast heating curve for un-deformed sample and after compression to $2,3.8$, and $4.8 \mathrm{GPa}$
X210CrW12 thixo-cast steel brought about a shift of the beginning of small exothermic reaction down to range 100 to $250{ }^{\circ} \mathrm{C}$. The large positive effect connected with austenite decomposition that started at above $558{ }^{\circ} \mathrm{C}$ and disappeared at about $677^{\circ} \mathrm{C}$ is shown in Fig. 5. The thermal effect in range 100 to $250{ }^{\circ} \mathrm{C}$ could be also connected with the precipitation of transition carbides such as $\chi-\mathrm{Fe}_{5} \mathrm{C}_{2}, \eta-\mathrm{Fe}_{2} \mathrm{C}$ (Ref 24) from the $\varepsilon$-Fe martensite (Ref 11). With increasing stress, huge peak movements to lower temperatures: unstressed sample- to $634^{\circ} \mathrm{C}$ and compressed ones to $2,3.8$ and $4.8 \mathrm{GPa}$ to 621 , 611 , and $599{ }^{\circ} \mathrm{C}$, respectively, was observed. It was confirmed in (Ref 16), that with increasing level of deformation of the supersaturated solid solution, the peak temperatures moved to lower ones. Similar effects of the movement of $\gamma$-Fe transformation temperature were visible in the hot deformed M2 tool steel, in which a high density of defects in the strained austenite resulted in the acceleration of diffusion-controlled phase transformations (Ref 17). Additionally, straining the austenitic phases raised the final hardness by 10 to $20 \%$ through the precipitation of very fine carbides (Ref 17).

Figure 6a shows a SEM microstructure of SSM processed $\mathrm{X} 210 \mathrm{CrW} 12$ steel heated up to $634{ }^{\circ} \mathrm{C}$ (temperature peak according to DSC analysis visible in Fig. 5) at rate $20^{\circ} \mathrm{C} / \mathrm{min}$, cooled next with the furnace. One can observe globular grains with $\alpha-\mathrm{Fe}$ and carbides nodules resulting from the decomposition of $\gamma$-Fe. The reaction started inwards from the grain boundaries surrounded by the eutectic mixture. The observed changes in the microstructure is somewhat similar to the discontinuous precipitation reaction in steel reported by Ainsley et al. in (Ref 25), who showed that the transformation $\gamma$ $\mathrm{Fe} \rightarrow \gamma_{1}-\mathrm{Fe}+\mathrm{VC}$ proceeded through the discontinuous precipitation, which started from the grain boundary. According to Bhadeshia (Ref 26) the decomposition of austenite can occur at temperatures above Bs (if the holding time is short enough) or below Bs (if the holding time is long). Such a transformation product has been classified as pearlite consisting of ferrite and $\mathrm{M}_{7} \mathrm{C}_{3}$ carbides.

The microhardness analysis (Fig 6b) shows that the hardness of dark-etched-area was about $700 \mathrm{HV}_{0.02}$, while that of light places (un-etched) in the center part of grains reached around $780 \mathrm{HV}_{0.02}$. It suggested, that in the center part of grains, a mixture of martensite and residual austenite (un-etched area) existed in front of lamellar pearlite. The hard $\alpha^{\prime}$-Fe phase
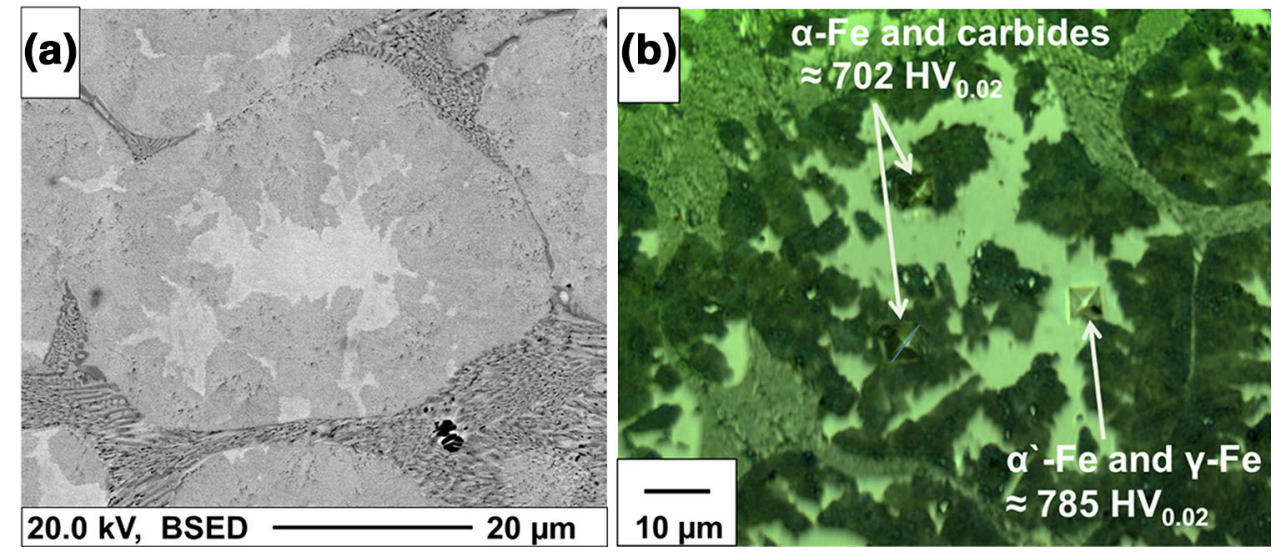

Fig. 6 (a) SEM micrograph of X210CrW12 steel after thixoforming and heating to $634{ }^{\circ} \mathrm{C}$, (b) optical microstructure with indentation marks of microhardness load at $200 \mathrm{mN}$ 
formed probably by the depletion of austenite in carbon, leading to the decrease of $M s$ temperature. The $\gamma$-Fe to $\alpha^{\prime}$-Fe transformation probably took place during cooling. The $\mathrm{x}$-ray analysis of the investigated steel confirmed the occurrence of ferrite, $\mathrm{M}_{7} \mathrm{C}_{3}$ carbides and residual austenite in the amount below 5 vol.\%. Similar results were obtained for the $\mathrm{X} 210 \mathrm{CrW} 12$ steel after SSM and tempered for $2 \mathrm{~h}$ at $525{ }^{\circ} \mathrm{C}$ (Ref 9).

In the TEM bright field micrograph (Fig. 7a), the areas similar to those appeared due to the discontinuous precipitation reaction were visible, in which a supersaturated $\gamma$-Fe matrix (right side of BF image) transformed into more thermodynamically stable mixture of very fine ferrite and carbides (the top left corner). The microstructure with morphology close to perlite could be also seen in the bottom left corner of Fig. 7a. According to Thompson (Ref 27), the composition of the matrix changed discontinuously across the reaction front. The electron diffraction pattern (Fig. 7b) from the light area shows reflections from the $\gamma$-Fe $(1-1-1)$ and $(02-2)$, which were indexed according to austenite zone axis [211]. The $\gamma$-Fe solid solution without carbides indicated a large supersaturation with alloying elements and carbon. Figure 7c shows SAEDP of the decomposed austenite giving reflections from $\mathrm{M}_{7} \mathrm{C}_{3}(0111)$ and $(-1100)$ of tetragonal lattice and corresponding zone axis [112-3] and $\alpha$-Fe [100]. The obtained phases are stable at room temperature according to the phase diagram of X210Crw12 steel (Ref 7). The typical, commonly known discontinuous reaction in steel is responsible for the transformation of austenite into perlite during slow cooling in eutectoid steels (Ref 28). The discontinuous precipitation in austenitic phase of Fe13Mn2V0.8C steel produces the $\gamma$-Fe phase and VC precipitates with either a fibrous or particulate morphology and (Ref 25).

The bright field micrograph (Fig 8) taken of a grain of $\mathrm{X} 210 \mathrm{CrW} 12$ thixo-cast after compression stress to $4.8 \mathrm{GPa}$ showed frequent twin bands within the austenitic grains, which revealed high density of defects. Additionally, the presence of $\varepsilon$-martensite of hexagonal lattice with numerous random stacking faults was confirmed in (Ref 11). According to the selected area electron diffraction pattern SAEDP (shown as the insert), strong reflections of the $\gamma$-Fe at zone axis orientation [110] with twins on $(1-11)$ plane are visible.
The decomposition caused by tempering of severely strained and supersaturated steel can lead to obtaining an uncommon product of transformation, which have influence on mechanical properties.

Heating the deformed sample up to $599{ }^{\circ} \mathrm{C}$ (temperature peak according to DSC analysis Fig. 5), resulted in a partial decomposition of residual austenite. The transformation started simultaneously from grain boundaries, twins and slip bands (Fig. 9a), which generated a high number of defects in the austenite. As can be seen in Fig. 9b, the lateral areas of the image showed the morphology of microstructure similar to lamellar. A high magnification obtained in the TEM analysis (Fig. 9c) revealed the pearlite structure in the selected part of middle area grains. In the central part of Fig. 9b the areas, in which carbides (marked by arrows) started nucleating at slip bands as well as at twins (marked by ring) are visible. Figure 9d shows the TEM-BF image with corresponding selected area DF of central parts of Fig 9b. It presents ferrite bands with carbide particles along the previous austenitic grain boundaries. The strong contrast suggests the presence of defects and carbides, which probably formed in the original orientation of deformed $\gamma$-Fe band. The SAEDP from plates and areas of

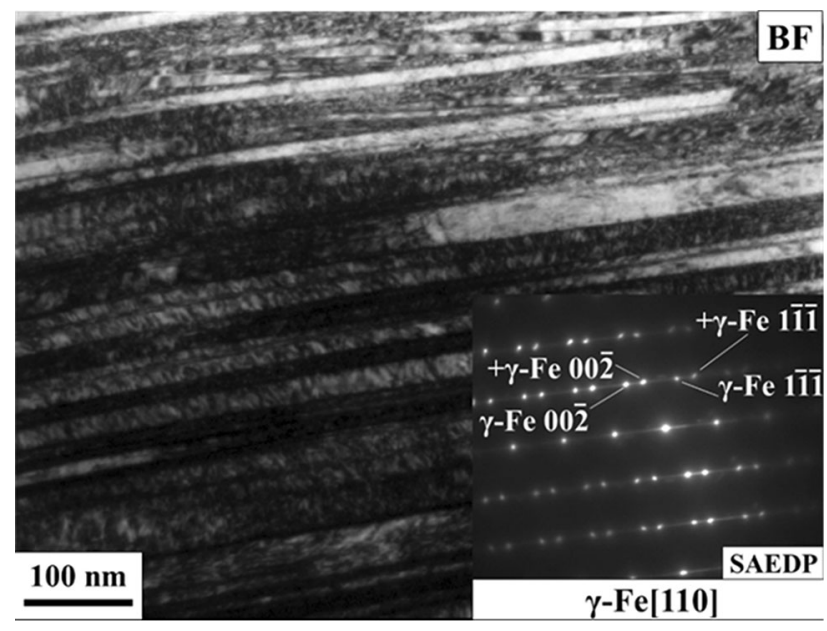

Fig. 8 TEM micrograph with SAEDP after compression to $4.8 \mathrm{GPa}$

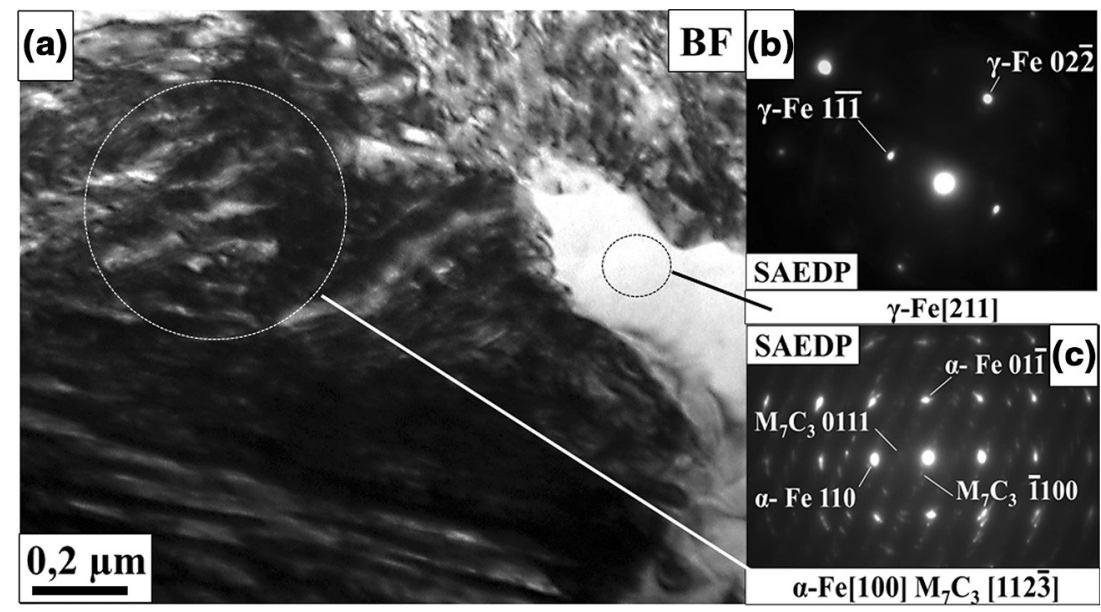

Fig. 7 (a) TEM-BF micrograph from area of discontinuous transformation of X210CrW12 thixo-cast steel heated up to $634{ }^{\circ} \mathrm{C}$, (b) SAEDP from un-transformed area of austenite, (c) SAEDP from the area after the front of discontinuous reaction passed 

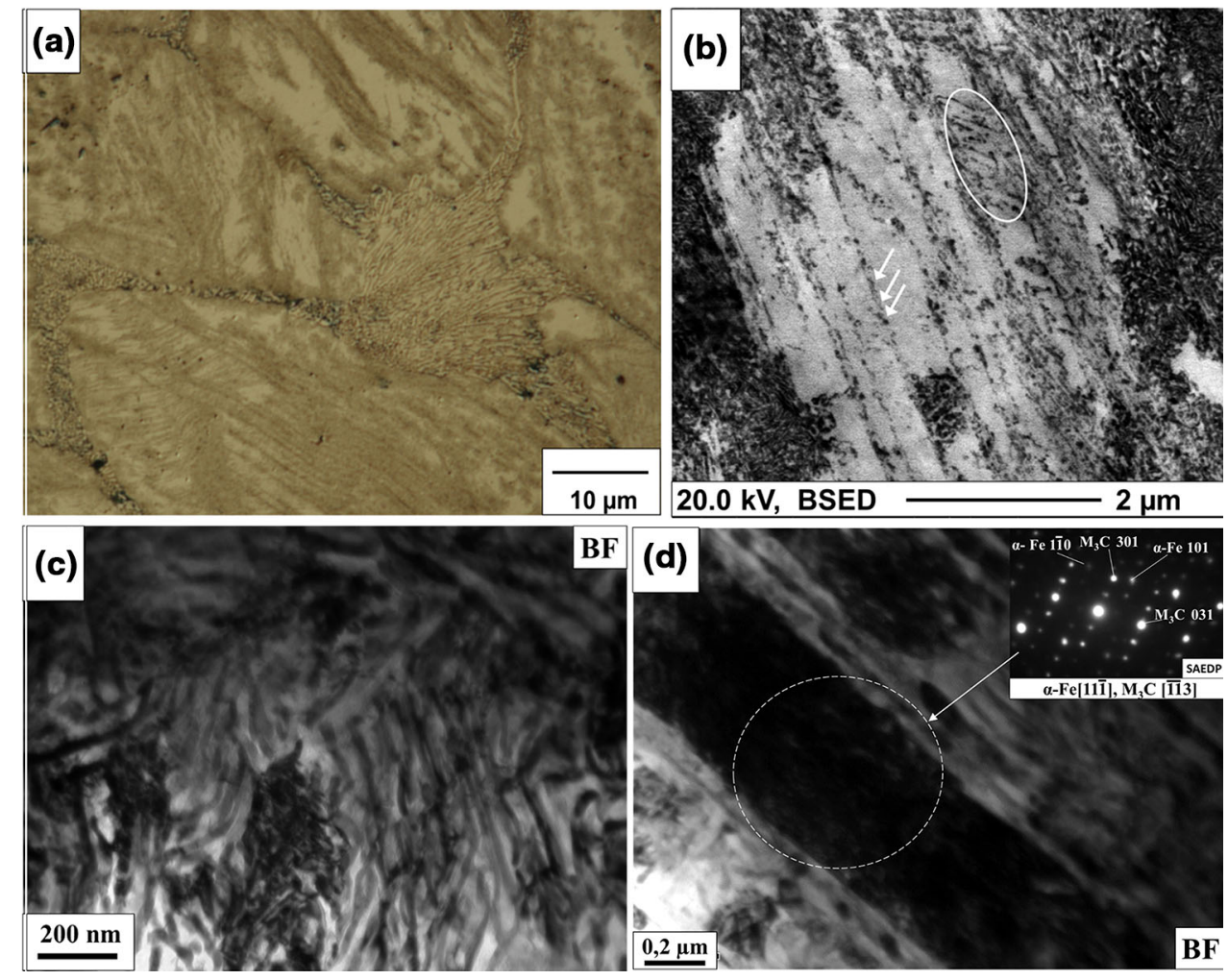

Fig. 9 (a) Microstructure of $4.8 \mathrm{GPa}$ stressed sample and heated to $599^{\circ} \mathrm{C}$, (a) optical microstructure, (b) SEM-BSE micrograph, (c) BF structure showing pearlite, (d) TEM-BF image showing bands with carbide particles along the previous austenitic deformation bands with corresponding SAED pattern

their boundaries (marked with dotted ring) shows strong reflections from $\alpha$-Fe [11-1] matrix and $\mathrm{Fe}_{3} \mathrm{C}$ carbides at zone axis $[-1-13]$. Such an area in steel may be the starting point for the discontinuous transformation due to the coagulation of carbides, which can lead to breaking the coherence with the matrix. It suggests that $\mathrm{M}_{3} \mathrm{C}$ carbides precipitated mainly at strongly deformed areas as a first product of strained austenite. The appearance of the $\mathrm{M}_{3} \mathrm{C}$ carbide might have been preceded by the precipitation of transient carbides $\left(\chi-\mathrm{Fe}_{5} \mathrm{C}_{2}, \eta-\mathrm{Fe}_{2} \mathrm{C}\right)$ probably present in the structure. The $\mathrm{x}$-ray analysis confirmed the presence of $\alpha$-Fe and $\mathrm{M}_{7} \mathrm{C}_{3}$ carbides in the sample strained $4.8 \mathrm{GPa} / 599{ }^{\circ} \mathrm{C}$ (Fig. 3). The content of $\mathrm{M}_{3} \mathrm{C}$ carbides was probably too small to be identified by $\mathrm{X}$-ray examination. Higher density of defects in the hot deformed austenite increased the heterogeneous nucleation rate and supported the carbide precipitation which has been shown in numerous works (Ref 17, 19, 29).

The microhardness measurements of $4.8 \mathrm{GPa} / 599{ }^{\circ} \mathrm{C}$ sample (Fig. 10) showed various hardness values across the grain. It was connected with the progress of $\gamma$-Fe decomposition. At places, where the front of discontinuous transformation passed forming the mixture of ferrite and $\mathrm{M}_{7} \mathrm{C}_{3}$ carbides, the hardness was relatively low; about $660 \mathrm{HV}_{0.02}$, while in the area with ferrite plates and $\mathrm{M}_{3} \mathrm{C}$ carbides it reached $900 \mathrm{HV}_{0.02}$. Slightly higher hardness in comparison with the unstressed sample was probably caused by the strain-induced transformation of grains.

The TEM-BF image (Fig. 11a) shows the interface between the front of discontinuous precipitation, in which previously decomposed austenite into mixture of $\mathrm{M}_{7} \mathrm{C}_{3}$ carbides and $\alpha-\mathrm{Fe}$ solid solution (right side of micrograph) reacted with $\alpha$-Fe plate and $\mathrm{M}_{3} \mathrm{C}$ formed as a result of plastic deformation (left side). It

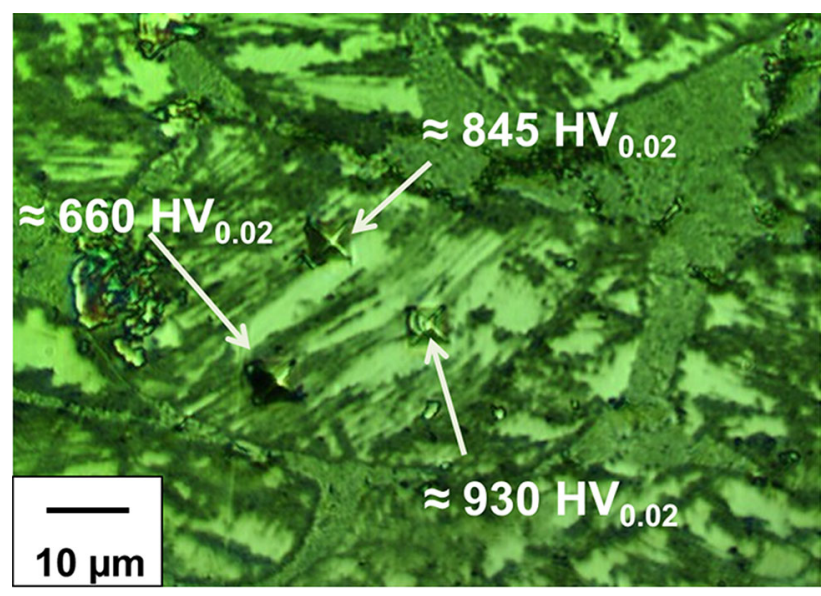

Fig. 10 Optical microstructure of compressed and heat-treated $\left(4.8 \mathrm{GPa} / 599^{\circ} \mathrm{C}\right)$ sample with indentation marks of microhardness at load of $200 \mathrm{mN}$

suggests that such a microstructure was not stable at $599{ }^{\circ} \mathrm{C}$ and transformed due to high diffusivity of carbon. Additionally, a new discontinuous precipitation was observed in comparison with the un-deformed material. The electron diffraction pattern (Fig 11b) from the left side of Fig 11b (area marked with dotted ring) shows reflections from $\gamma$-Fe (211) and (011), which were indexed according to ferrite zone axis [0-11]. Reflections from $\mathrm{M}_{7} \mathrm{C}_{3}$ carbides $(01-10)$ and $(-1-122)$ with hexagonal lattice and $[20-2-1]$ zone axis are also visible in the SAEDP. Figure 11c shows the SAEDP from the area of microstructure 


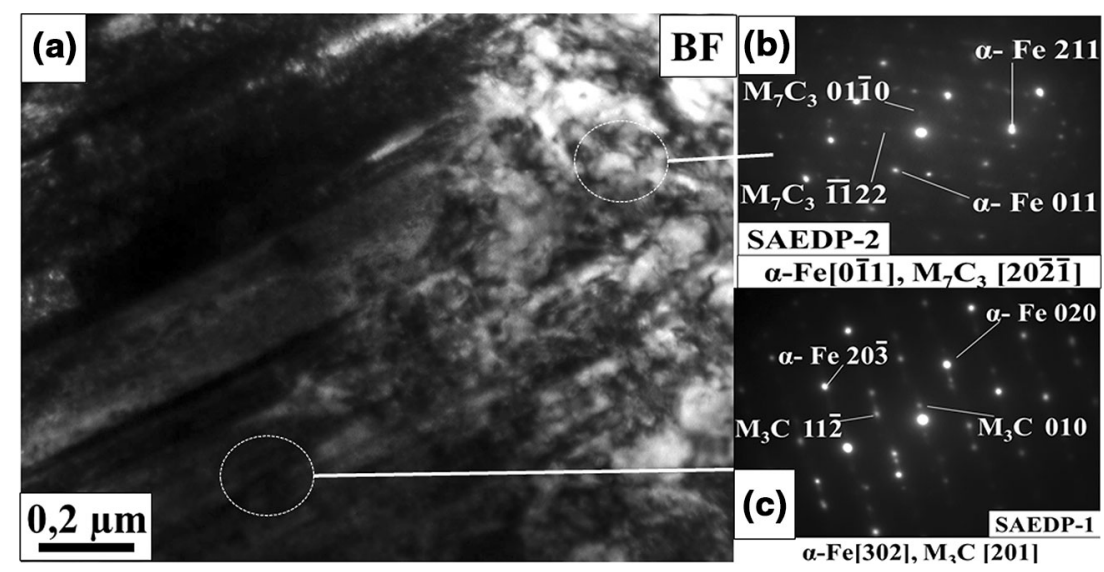

Fig. 11 (a) TEM-BF micrograph of discontinuous transformation area of $\mathrm{X} 210 \mathrm{CrW} 12$ thixo-cast steel deformed and heated up to $599{ }^{\circ} \mathrm{C}$, (b) SAEDP from area after transformation of austenite into the mixture of $\alpha$-Fe and $\mathrm{M}_{7} \mathrm{C}_{3}$ carbides, (c) SAEDP from the area before discontinuous transformation

marked with dotted ring giving reflections from the orthorhombic $\mathrm{MC}_{3}$ carbide $(11-2)$ and $(010)$ corresponding zone axis $[112-3]$ and $\alpha-F e$ [302]. It suggests that the decomposition of austenite by discontinuous precipitation mechanism played the crucial role in the deformed steel. In contrast to non-deformed state they cover the area of grains. An additional front of reaction $\alpha$-Fe plate $+\mathrm{M}_{3} \mathrm{C} \rightarrow$ mixture of $\alpha$-Fe and $\mathrm{M}_{7} \mathrm{C}_{3}$ carbides was also observed. Similar mechanisms were observed by Shtansky (Ref 30) in the Fe17Cr0.5C steel tempered at $735{ }^{\circ} \mathrm{C} / 10 \mathrm{~s}$, in which the martensite transformed by discontinuous-like precipitation into the mixture of cementite, $\alpha-\mathrm{Fe}$, and carbides: $\mathrm{M}_{23} \mathrm{C}_{6}$ and $\mathrm{M}_{7} \mathrm{C}_{3}$. Various carbide morphologies were observed close to the reaction front: rod-like, spherical, or lamellar.

\section{Conclusion}

X210CrW12 thixo-cast steel consisted of austenitic globular grains surrounded by eutectic mixture with average hardness $455 \mathrm{HV}$. Metastable austenite in as thixo-cast state decomposed at $634{ }^{\circ} \mathrm{C}$, according to DSC analysis, leading to increase of hardness up to $743 \mathrm{HV}$. Deformation by compression to 2, 3.8, and $4.8 \mathrm{GPa}$ decreased temperature of decomposition to 621 , $611,599{ }^{\circ} \mathrm{C}$, respectively. The discontinuous transformation of austenite into perlite, which started mainly at grain boundaries and forwarded to the center was predominant mechanism responsible for the transformation of globular grains in undeformed X210CrW12 thixo-cast steel. In the deformed sample the reaction started on slip bands and twins which revealed high density of defects, leading to precipitation of carbides, followed by local depletion in carbon as a result of $\alpha^{\prime}$-Fe formation. Further reaction resulted in changes of $M_{3} C$ carbides to $M_{7} C_{3}$. In contrast to un-deformed state they covered the area of grains, leading to increase of hardness up to $812 \mathrm{HV}$.

\section{Acknowledgments}

The research was supported by Polish science financial resources Applied Research Programme of the National Centre for Research and Development in Poland; "Developing a technol- ogy of producing complex elements by steel thixoforming" PBS1/ B5/22/2013.

\section{Open Access}

This article is distributed under the terms of the Creative Commons Attribution 4.0 International License (http://creativecommons.org/ licenses/by/4.0/), which permits unrestricted use, distribution, and reproduction in any medium, provided you give appropriate credit to the original author(s) and the source, provide a link to the Creative Commons license, and indicate if changes were made.

\section{References}

1. W. Püttgen, B. Hallstedt, W. Bleck, and P.J. Uggowitzer, On the Microstructure Formation in Chromium Steels Rapidly Cooled from the Semi-Solid State, Acta Mater., 2007, 55(3), p 1033-1042

2. Kapranos P, Kirkwood DH, Sellars CM (1992) Semi-solid forging of high temperature alloys. Proceedings of the Second International Conference on the Processing of Semi-Solid Alloys and Composites, Cambridge, p 119-129

3. Z. Fan, Semisolid Metal Processing, Int. Mater. Rev., 2002, 47(2), p 49-85

4. H.V. Atkinson and A. Rassili, Thixoforming Steel, Shaker Verlag, Aachen, 2010

5. Ł. Rogal and J. Dutkiewicz, Effect of Annealing on Microstructure, Phase Composition and Mechanical Properties of Thixo-Cast 100Cr6 Steel, J. Mater. Charact., 2012, 68, p 123-130

6. W. Püttgen, B. Hallstedt, W. Bleck, J.F. Loffler, and P.J. Uggowitzer, On the Microstructure and Properties of $100 \mathrm{Cr} 6$ Steel Processed in the Semi-Solid State, Acta Mater., 2007, 55(19), p 6553-6560

7. G. Hirt and R. Kopp, Thixoforming: Semi-Solid Metal Processing, Wiley-VCH Verlag GmbH \& Co. KGaA, Aachen, 2009

8. B. Masek, D. Aisman, M. Behulova, and H. Jirkova, Structure of Miniature Components from Steel Produced by Forming in Semi-Solid, Trans. Nonferr. Met. Soc. China, 2010, 20(3), p 1037-1041

9. Ł. Rogal and J. Dutkiewicz, Heat Treatment of tHixo-Formed Hypereutectic X210CrW12 Tool Steel, Metall. Mater. Trans. A, 2012, 43A(13), p 5009-5018

10. W. Püttgen, B. Hallstedt, W. Bleck, and P.J. Uggowitzer, On the Microstructure Formation in Chromium Steels Rapidly Cooled from the Semi-Solid State, Acta Mater., 2007, 55/3, p 1033-1042

11. Ł. Rogal and J. Dutkiewicz, Deformation Behavior of High Strength X210CrW12 Steel After Semi-Solid Processing, Mater. Sci. Eng. A, 2014, 603, p 93-97 
12. D. Aisman, H. Jirkova, and B. Masek, The Influence of Deformation and Cooling Parameters After Transition Through Semi-Solid State on Structure Development of Ledeburite Steel, J. Alloy Compd., 2012, 536, p 204-207

13. T.V. Pirtovšek, G. Kugler, M. Godec, and M. Terčelj, Microstructural Characterization During the Hot Deformation of 1.17C-11.3Cr-1.48 V2.24 W-1.35Mo Ledeburitic Tool Steel, Mater. Charact., 2011, 62, p 189-197

14. R. Wilson, Metallurgy and Heat Treatment of Tool Steel, McGraw-Hill Book, New York, 1975

15. A.P. Gulâev. Metallovedenije. Slask Katowice, 1969

16. J. Nutting, The Influence of Plastic Strain Upon the Aging Characteristics of Alloys, Metall. Trans., 1971, 2(1), p 45-51

17. Konopleva EV, Khlestov VM, McQueen HJ (1995) Phase Transformation During Thermal/Mechanical Processing of Steel, In: E.B. Hawbolt and S. Yue, Eds., Met. Soc. CIM, p 243-258

18. D.V. Wilson, Effects of Plastic Deformation on Carbide Precipitation in Steel, Acta Metall., 1957, 5, p 293-302

19. D. Jandová, Influence of Hot and Warm Deformation on Austenite Decomposition, J. Achiev. Mater. Manuf. Eng., 2006, 18, p 375-378

20. A. Saeed-Akbari, L. Mosecker, A. Schwedt, and W. Bleck, Characterization and Prediction of Flow Behaviour in High-Manganese Twinning Induced Plasticity Steels: Part I: Mechanism Maps and Work-Hardening Behavior, Metall. Mater. Trans. A, 2012, 43A, p 1688-1704
21. K.H. Kwon, B.C. Suh, S.I. Baik, Y.W. Kim, J.K. Choi, and N.J. Kim, Deformation Behavior of Duplex Austenite and $\varepsilon$-Martensite High-Mn Steel, Sci. Technol. Adv. Mater., 2013, 14, p 1-8

22. V. Tsakiris and D.V. Edmonds, Martensite and Deformation Twinning in Austenitic sTeels, Mater. Sci. Eng. A, 1999, 273, p 430-436

23. K. Sato, M. Ichinose, Y. Hirotsu, and Y. Inoue, Effects of Deformation Induced Phase Transformation and twInning on the Mechanical Properties of Austenitic Fe-Mn-AI, Alloys ISIJ Int., 1989, 29, p 868-877

24. V.A. Shabashov, L.G. Korshunov, A.G. Mukoseev, V.V. Sagaradze, A.V. Makarov, and V.P. Pilyugin, Deformation-Induced Phase Transitions in a High-Carbon Steel, Mater. Sci. Eng. A, 2003, 346, p 196-207

25. H. Ainsley, G.J. Cocks, and D.R. Miner, Influence of Grain Boundary Structure on Discontinuous Precipitation in Austenitic Steel, Met. Sci., 1979, 13(1), p 20-24

26. H.K.D.H. Bhadeshia, Microstructure Bainite in Steel-Transformation and Properties, 2nd ed., University Press, Cambridge, 2001

27. M.N. Thompson, Ph.D. Thesis, University of Cambridge, 1971

28. R.W. Cahn, P. Haasen, Physical Metallurgy, Tom No. 1, 1996

29. V.M. Khlestov, E.V. Konopleva, and H.J. McQueen, Effects of Deformation and Heating Temperature on the Austenite Transformation to Pearlite in High Alloy Tool Steels, Mater. Sci. Technol., 2002, 18, p 54-60

30. D.V. Shtansky, K. Nakai, and Y. Ohmor, Decomposition of Martensite by Discontinuous- Like Precipitation Reaction in an Fe17Cr0.5C Alloy, Acta Mater., 2000, 48, p 969-983 